\title{
A comparative study of the oxidation characteristics of two gasoline fuels and an n-heptane/iso-octane surrogate mixture
}

Tamour Javed, Ehson F. Nasir, Et-touhami Es-sebbar, Aamir Farooq*

Clean Combustion Research Center, Division of Physical Sciences and Engineering, King Abdullah University of Science and Technology (KAUST), Thuwal, 23955-6900, Saudi Arabia

*Corresponding author. Email: aamir.farooq@kaust.edu.sa, Phone: +966128082704 


\begin{abstract}
Ignition delay times and $\mathrm{CO}, \mathrm{H}_{2} \mathrm{O}, \mathrm{OH}$ and $\mathrm{CO}_{2}$ time-histories were measured behind reflected shock waves for two FACE (Fuels for Advanced Combustion Engines) gasolines and one PRF (Primary Reference Fuel) blend. The FACE gasolines chosen for this work are primarily paraffinic and have the same octane rating $(\sim \mathrm{RON}=84)$ as the PRF blend, but contain varying amounts of iso- and n-paraffins. Species time-histories and ignition delay times were measured using laser absorption methods over a temperature range of $1350-1550 \mathrm{~K}$ and pressures near 2 atm. Measured species time-histories and ignition delay times of the PRF blend and the two FACE fuels agreed reasonably well. However, when compared to recent gasoline surrogate mechanisms, the simulations did not capture some of the kinetic trends found in the species profiles. To our knowledge, this work provides some of the first shock tube species time-history data for gasoline fuels and PRF surrogates and should enable further improvements in detailed kinetic mechanisms of gasoline fuels.
\end{abstract}

\title{
Keywords
}

FACE gasoline; primary reference fuel; octane number; species time history; shock tube. 


\section{Introduction}

Gasoline is the most widely used transportation fuel for light duty vehicles. Gasoline is primarily comprised of hydrocarbons in $\mathrm{C}_{4}-\mathrm{C}_{10}$ range [1], however, the actual composition varies significantly depending primarily on the geographic origin of the fuel [2]. As such the commercial transportation-grade gasoline is a complex mixture of hundreds of hydrocarbons including linear and branched paraffins, naphthenes, olefins and aromatics. It becomes extremely inefficient to accommodate all of these species in any real world computational/experimental scenario. These difficulties can be overcome by considering a surrogate mixture of a few wellknown components in a well-defined composition to emulate the target properties of the real fuel. Generally, these target properties include desired combustion characteristics (ignition delay, flame speed, etc.) and/or physical properties (molecular weight, H/C ratio, distillation curve, etc.). However, it should be noted that a given surrogate may not be able to match all physical and kinetics targets simultaneously. A conventional scale for rating the ignition properties of gasoline fuels is the research octane number $(\mathrm{RON})$ and/or the motor octane number (MON) based on blends of gasoline primary reference fuels (PRF), n-heptane and iso-octane. Blends of primary reference fuels have previously been used as gasoline surrogates. The chemical kinetics of PRFs has been studied quite comprehensively over the last decade or so. Work by Curran et al. [3, 4] on n-heptane/iso-octane and by Mehl et al. [5] on gasoline surrogates provide good account of the experimental and chemical kinetic modeling studies of primary reference fuels. Ignition delay times of PRF blends have been measured previously by a few groups [6-8]. More complex multi-component gasoline surrogates have been proposed in ignition delay studies under HCCI-like conditions [9-11]. 
The US Department of Energy and the Coordinating Research Council comprising of research institutes, automotive and oil companies have recently formulated a set of fuels, known as Fuels for Advanced Combustion Engines (FACE). One of the basic aims of formulating these FACE fuels is to provide a consistent set of fuels with well-characterized properties and compositions, making it easy to compare research results at various institutions and facilities. In the current study, we have investigated the oxidation characteristics of FACE gasoline A and C. Error! Reference source not found. shows some of the key features of these two fuels; more detailed compositional analysis of FACE gasoline and diesel fuels can be found in [12, 13]. Both gasolines have very similar octane rating but they differ in their compositions; FACE C has more than double the amount of n-paraffins than FACE A. Also, small amount $(\sim 4 \%)$ of aromatics is present in FACE C but are almost negligible in FACE A. The two gasoline fuels are compared here against a PRF blend of $84 \%$ iso-octane / 16\% n-heptane (by volume), referred to as PRF 84 in this work.

Chemical kinetics models are often validated against global kinetics targets such as ignition delay and flame speed data obtained from shock tubes, rapid compression machines, and simple canonical flames. Such data provide an overall view of the kinetic mechanism behavior and its ability to predict fuel reactivity but these data cannot be used to validate complex reaction pathways which are important, for example, in predicting emissions. The detailed chemical kinetics also play important role in controlling the fuel reactivity under HCCI- or PCCI- like conditions. Comprehensive validation of detailed chemical kinetic mechanism would benefit greatly by experimentally measured species time-history profiles. Shock tube / laser absorption experiments are particularly well-suited for acquiring species time-history data [14-18] because 
of the step change in test conditions behind shock waves, the highly uniform temperatures and pressures, and the fast time response of laser absorption diagnostics.

Error! Reference source not found. shows the predictions for the evolution of five major species formed during the oxidation of PRF 84. Simulations are carried out using gasoline surrogate mechanism of Mehl et al. [5] with constant internal energy and volume (constant UV) gasdynamic model in Chemkin-Pro [19]. The fuel decomposes immediately within the first $10-$ $50 \mu$ s producing fuel fragments, $\mathrm{C}_{1}-\mathrm{C}_{4}$ intermediate species and an active radical pool. The concentrations of the reaction progress markers $\left(\mathrm{CO}, \mathrm{H}_{2} \mathrm{O}\right.$ and $\left.\mathrm{CO}_{2}\right)$ increase slowly at early times, over the $50-450 \mu$ s window in this example, until there is an exponentially fast growth of $\mathrm{OH}$ radicals and significant energy release from the $\mathrm{CO}+\mathrm{OH} \leftrightarrow \mathrm{CO}_{2}+\mathrm{H}$ reaction. Post-ignition $\mathrm{CO}_{2}$ and $\mathrm{H}_{2} \mathrm{O}$ concentrations will eventually approach their equilibrium values governed primarily by their thermochemical properties. Details of the species time-histories in the preignition region are very important, and can provide very stringent constraints on mechanism prediction and validation.

In this study, we present species time-history and ignition delay time measurements for FACE gasolines $\mathrm{A}$ and $\mathrm{C}$ as well as a PRF 84 surrogate. Measurements are performed over a temperature range of $1350-1550 \mathrm{~K}$ and at pressures near 2 atm. In all experiments, the fuel concentration was kept at $0.2 \%$ with an equivalence ratio of 1 and argon is the diluent gas. Timehistories of $\mathrm{OH}, \mathrm{CO}, \mathrm{CO}_{2}$ and $\mathrm{H}_{2} \mathrm{O}$ were measured using laser-based UV and IR absorption spectroscopy. The reactivity and speciation of the three fuels were compared based on the fuel composition and also compared with predictions from recent gasoline surrogate mechanisms. 


\section{Methedology}

\subsection{Chemical kinetics shock tube facility}

All experiments were performed in the chemical kinetics shock tube facility at King Abdullah University of Science and Technology (KAUST). This shock tube facility has been reported previously in literature [20-22] and only a brief account will be given here. The stainless steel shock tube has an inner diameter of $14.2 \mathrm{~cm}$, driven section is $9 \mathrm{~m}$ long and a modular driver section with maximum length of $9 \mathrm{~m}$. The driven section can be pumped down to $1 \times 10^{-6}$ mbar using a turbomolecular pump. As the gasoline and PRF surrogate are multi-component fuels, the mixtures were prepared by direct injection of the fuel into a heated $\left(75^{\circ} \mathrm{C}\right)$ mixing vessel, equipped with a magnetically driven stirrer. These liquid fuels can readily adsorb on the mixing vessel walls and shock tube inner surface. The mixture composition was measured by Fourier Transform Infrared (FTIR) absorption spectroscopy by taking samples from the mixing vessel and the shock tube. The sampled mixtures were found to be within $5 \%$ of the manometrically determined values. Additionally, partial pressure of the fuel was kept well below the saturation vapor pressure relatively to avoid fuel condensation. The PRF 84 blend was prepared volumetrically using high purity (>99.5\%) n-heptane and iso-octane (Sigma-Aldrich). FACE gasoline A and C were obtained from Conoco Philips Specialty Chemicals and researchgrade argon and oxygen were supplied by AHG Gases.

Incident shock velocity was calculated by measuring the time interval between five PCB 113B26 piezoelectric pressure transducers (PZTs) that were located axially along the last $1.3 \mathrm{~m}$ of the driven section. The incident shock speed at the end-wall was determined by linear 
extrapolation of the velocity profile. One-dimensional shock-jump equations were used to calculate the conditions $\left(\mathrm{T}_{5}, \mathrm{P}_{5}\right)$ behind reflected shock wave. Thermodynamic parameters used for argon, oxygen and PRF (iso-octane/n-heptane) were taken from Sandia thermodynamic database [23]. A complex 20 component thermodynamic surrogate, based on detailed hydrocarbon analysis, was used for FACE gasoline A and C. The uncertainty in the calculated temperatures and pressures is less than $\pm 1 \%$ with the major contribution coming from uncertainties in the incident shock speed and mixture composition.

\subsection{Laser diagnostics}

Four laser absorption diagnostics were used to simultaneously monitor the concentration time-histories of $\mathrm{CO}, \mathrm{CO}_{2}, \mathrm{H}_{2} \mathrm{O}$ and $\mathrm{OH}$. These diagnostics have either been validated previously $(\mathrm{CO}, \mathrm{OH})$ or were characterized in separate non-reactive experiments conducted in our shock tube facility $\left(\mathrm{CO}_{2}, \mathrm{H}_{2} \mathrm{O}\right)$. These diagnostics enabled us to make extremely sensitive measurements with relatively low detectivity limits at the conditions of our experiments: 1 ppm for $\mathrm{OH}, \sim 10 \mathrm{ppm}$ for $\mathrm{CO}$ and $\sim 100 \mathrm{ppm}$ for $\mathrm{CO}_{2}$ and $\mathrm{H}_{2} \mathrm{O}$. The overall uncertainty in these speciation measurements is $<5 \%$ and primarily comes from uncertainty in absorption crosssection, post-shock temperature $\left(\mathrm{T}_{5}\right)$ and calculation of temperature time-history (see Section 2.3). A brief description of each diagnostic is provided below:

\subsubsection{IR absorption of CO using a DFB QCL:}

Carbon monoxide concentration was monitored near $2193.36 \mathrm{~cm}^{-1}$ in the fundamental vibrational band of $\mathrm{CO}$ using a distributed-feedback (DFB) quantum cascade laser (QCL). The

line-broadening parameters for this line were measured by Ren et al. [24] and line-strength values were obtained from the HITRAN database [25]. A small amount of absorption 
interference is caused by $\mathrm{CO}_{2}$ at high temperatures. This was corrected by measuring $\mathrm{CO}_{2}$ absorption cross-section at this wavelength $\left(2193.36 \mathrm{~cm}^{-1}\right)$ in separate $\mathrm{CO}_{2} / \mathrm{Ar}$ shock-heated experiments. The $\mathrm{CO}_{2}$ interference was then subtracted from the measured $\mathrm{CO}$ absorption profiles using the $\mathrm{CO}_{2}$ mole fraction measurements.

\subsubsection{IR absorption of $\mathrm{CO}_{2}$ using an external-cavity $Q C L$ :}

An external-cavity QCL was used at a fixed wavelength for laser absorption of $\mathrm{CO}_{2}$. The

$\mathrm{R}(76)$ line at $2390.52 \mathrm{~cm}^{-1}$ in the $v_{3}$ vibrational band of $\mathrm{CO}_{2}$ was selected due to its relatively high lower-state energy and minimal interference from other species. High-temperature crosssections of $\mathrm{CO}_{2}$ at the peak of the transition were measured in our shock tube using $\mathrm{CO}_{2} / \mathrm{Ar}$ mixtures and verified with previous measurements by Ren et al. [26, 27].

\subsubsection{IR absorption of $\mathrm{H}_{2} \mathrm{O}$ using a DFB diode laser:}

$\mathrm{H}_{2} \mathrm{O}$ concentrations were monitored using a distributed feedback (DFB) diode laser operating at $3416.16 \mathrm{~cm}^{-1}$ in the $v_{3}$ vibrational band of $\mathrm{H}_{2} \mathrm{O}$. This line provides increased absorption strength compared to the transitions used in previous $\mathrm{H}_{2} \mathrm{O}$ sensing work [28, 29]. Absorption cross-sections for this transition were measured in separate experiments of shockheated mixtures of $\mathrm{H}_{2} \mathrm{O} / \mathrm{Ar}$. The measured $\mathrm{H}_{2} \mathrm{O}$ absorption cross-sections are provided in Supplementary Material.

\subsection{4. $\mathrm{UV}$ absorption of $\mathrm{OH}$ using a ring-dye laser:}

Hydroxyl concentrations were measured using frequency doubling of $613.4 \mathrm{~nm} \mathrm{cw}$ light generated by a Spectra Physics ring-dye laser system. This ring-dye laser system was pumped by a Coherent Verdi laser operating at $532 \mathrm{~nm}$. The $\mathrm{R}_{1}(5)$ transition near $306.7 \mathrm{~nm}$ in the $\mathrm{OH} \mathrm{A}-\mathrm{X}$ $(0,0)$ absorption band was probed to measure $\mathrm{OH}$ mole fraction [30]. Negligible interference absorption was observed for FACE A and PRF 84. However, small interference absorption was 
detected at $306.7 \mathrm{~nm}$ during FACE C ignition experiments. This interference was corrected for by making off-line measurements, $5 \mathrm{~cm}^{-1}$ away from the peak of selected $\mathrm{OH}$ absorption transition.

\subsection{Calculation of temperature time-history}

Beer-Lambert law for spectrally narrow radiation can be written as $I / I_{o}=\exp (-$ $\left.S P L \phi_{v} X\right)$, where $I / I_{o}$ is the ratio of transmitted and incident laser intensities, $S(T)$ is the linestrength, $P$ is the total pressure, $L$ is the laser path-length, $\phi_{v}(T, P)$ is the line-shape function and $X$ is the mole fraction of the absorbing species. The line-strength and line-shape are temperaturedependent quantities and their variation with temperature is either known from a spectral database or determined via line characterization experiments. For shock tube experiments, the temperature behind reflected shock wave $\left(T_{5}\right)$ is calculated from the measured incident shock speed and thermodynamic parameters of the gas mixture. In non-reactive shock tube experiments, the $\mathrm{T}_{5}$ remains almost constant throughout the test time $(\sim 2 \mathrm{~ms})$. However, in reactive experiments, energy release from exothermic combustion reactions can cause the temperature to increase substantially during and after the ignition event. Thus a temperature time-history is needed to accurately calculate the mole fraction time-history using Beer's law. In the absence of direct temperature measurement, a temperature profile simulated by a chemical kinetic mechanism is used for the calculation of temperature-dependent spectroscopic quantities, i.e., line-strength and line-shape functions. Shock tubes are usually modeled with constant volume and constant internal energy (constant UV) constraints. However, these constraints are not suitable for situations where sufficient energy release takes place. In this work, we imposed the measured-pressure profile in Chemkin-Pro [19] and solved the energy equation to calculate 
temperature time-history. This modeling approach, referred to as UMP (constant internal energy with measured pressure profile), is used throughout the paper to generate temperature timehistories for converting measured absorbance profiles to concentration time-histories. This approach is demonstrated in Fig. 2, and compared with calculations using constant UV constraints and the ChemShock code proposed by the Stanford University group [31]. As expected, the constant UV simulations greatly overpredict the temperature and pressure. The temperature time-histories calculated using UMP and ChemShock are essentially similar, though the UMP approach is easier to implement.

\section{Validation of laser diagnostics}

Since chemical kinetic mechanisms for n-heptane are very well-validated, species timehistory profiles were initially measured during the oxidation of n-heptane stoichiometric mixtures to validate the laser diagnostics and the temperature modeling strategy. Measurements were carried out in a mixture of $0.2 \% \mathrm{n}$-heptane/oxygen/argon over a range of temperatures $(1350-1500 \mathrm{~K})$ and pressures near 2 atm. A representative dataset is shown in Fig. 3 at a reflected shock temperature of $1440 \mathrm{~K}$. The measured and simulated profiles (using Mehl et al. [5] mechanism) are generally in good agreement with some minor differences. For example, the mechanism overpredicts $\mathrm{H}_{2} \mathrm{O}$ production and underpredicts $\mathrm{CO}$ production at relatively early times of $50-100 \mu \mathrm{s}$. It is expected that all of the fuel carbon will get converted to $\mathrm{CO}$ and $\mathrm{CO}_{2}$ in the post-ignition region. Carbon balance can be calculated in the post-ignition region for validating the $\mathrm{CO}$ and $\mathrm{CO}_{2}$ diagnostics. At an elapsed time of $700 \mu$ s, the sum of measured $\mathrm{CO}$ and $\mathrm{CO}_{2}$ mole fractions is $13100 \mathrm{ppm}$ which is within $6.5 \%$ of the initial fuel carbon (14000 ppm). 


\section{Results and discussion}

\subsection{Ignition delay times of FACE gasolines and PRF surrogate}

Ignition delay times were measured for the two FACE gasolines and PRF 84 blend over a temperature range of $1330-1550 \mathrm{~K}$ and pressures near 2 atm; results are shown in Fig. 4. Ignition delay times were determined by the time interval between the arrival of the reflected shock wave and the extrapolation of the steepest rise in pressure signal to the pre-ignition level. All ignition delay time results are scaled to $2 \mathrm{~atm}$ using $P^{-1}$ pressure scaling. FACE gasoline A and $\mathrm{C}$ have the same overall reactivity indicated by very similar ignition delay times within the uncertainty limits of these experiments $(\sim 15 \%)$. It is well known [32-34] that increasing the branched hydrocarbon and/or aromatic content in the fuel decreases overall reactivity while nparaffins increase the reactivity. FACE gasoline $\mathrm{C}$ has almost double the amount of n-paraffins compared to FACE gasoline A. However, FACE gasoline $\mathrm{C}$ has about 5\% aromatics which balances out the higher reactivity due to increased n-paraffins, resulting in similar octane rating and similar ignition delays for both gasolines. Also evident in Fig. 4 is that PRF 84 surrogate captures the reactivity of these gasoline fuels over the entire temperature range of this study. This can be explained by the fact that both gasolines and the PRF blend are primarily paraffinic in nature $(\sim 95 \%$ paraffinic content $)$ and thus exhibit similar reactivity. This is consistent with surrogate fuel formulation strategy proposed by Dooley et al. [35] for jet fuels. They argued that the composition of the surrogate does not necessarily need to emulate all of the functional classes present in the real fuel. The composition of the surrogate should be such that it is able to emulate closely the development of the active radical pool and $\mathrm{C}_{1}-\mathrm{C}_{4}$ intermediate species which control the chemical kinetics phenomena at high temperatures. From the current study, it can be concluded that a PRF surrogate, having similar octane rating and $\mathrm{H} / \mathrm{C}$ ratio, can be used to 
capture the global reactivity of a predominantly paraffinic gasoline fuel under high temperature conditions. Measured ignition delay times are provided in a tabular form in the Supplementary Material.

Comparisons of measured ignition delay times with predictions from Mehl et al. [5] and Bieleveld et al. [36] gasoline surrogate mechanism are also shown in Fig. 4. The primary difference between the two mechanisms is that Bieleveld et al. [36] use lumped component/reaction method developed by Ranzi and coworkers [37] whereas Mehl et al. [5] consider all isomers and reaction pathways. Mehl et al. [5] mechanism overpredicts the experimental ignition delay times of the PRF surrogate and the two FACE gasolines over the entire temperature range of this study, whereas Bieleveld et al. [36] mechanism underpredicts the experimentally measured ignition delay times. It can also be seen from Fig. 4 that the Mehl et al. [5] mechanism predictions are closer to the experimental data at higher temperatures but exhibit relatively large deviations as temperature decreases. On the contrary, Bieleveld et al. [36] mechanism is closer to the experimental data at lower temperatures. The high-temperature chemistry is generally considered to be well established for reference fuels, such as n-heptane and iso-octane. Therefore, it is surprising that both mechanisms are unable to accurately predict the high-temperature ignition delay times of the PRF blend. Also shown in Fig. 4 are the experimental ignition delay times measured in our laboratory for n-heptane and iso-octane stoichiometric mixtures under similar conditions. Mehl et al. [5] mechanism captures n-heptane reactivity very well but overpredicts iso-octane ignition delay times. Thus it can be argued that the Mehl et al. [5] overprediction of PRF 84 ignition delay times is caused by iso-octane kinetic mechanism or the blending of n-heptane and iso-octane chemistry. The kinetics of iso-octane and 
related smaller branched intermediates, like iso-butene, must be evaluated further to improve the discrepancy between the measurements and the model.

\subsection{Species time-histories of FACE gasolines and PRF surrogate}

Species time histories were measured for the two FACE gasolines and the PRF surrogate over $1350-1550 \mathrm{~K}$ and nominal pressures of 2 atm. Fig. 5 (a-d) shows the measured profiles of $\mathrm{OH}, \mathrm{CO}, \mathrm{H}_{2} \mathrm{O}$ and $\mathrm{CO}_{2}$ during the stoichiometric oxidation of $0.2 \%$ fuel (PRF 84, FACE A, FACE C) at a representative temperature of $1450 \mathrm{~K}$. Although all four species are measured simultaneously for a specific fuel, the profiles shown for different fuels were measured in separate experiments; thus the actual reflected shock temperatures are $1450 \pm 10 \mathrm{~K}$. Both FACE $\mathrm{A}$ and $\mathrm{C}$ show very similar trends in all four species profiles. Also, PRF 84 surrogate captures the speciation profiles of both gasoline fuels reasonably well. These trends are consistent with the similarities found in ignition delay (Fig. 4) of all three fuels studied here. The chemical kinetics phenomena at high temperatures are primarily controlled by the presence of active radical pool such as $\mathrm{OH}, \mathrm{CH}_{3}, \mathrm{H}$, and $\mathrm{HO}_{2}$. If two fuels produce very similar active radical pool, it is expected that the fuels will then exhibit similar reactivity. Thus the PRF surrogate needs to reproduce the active radical pool of the real fuel as closely as possible in order to capture the chemical kinetics of the real fuel. It can be seen from Fig. 5 (a) that both gasoline fuels and PRF 84 show very similar trends in $\mathrm{OH}$ formation and consumption. The pre-ignition $\mathrm{OH}$ concentrations for PRF 84 and FACE A oxidation are in close agreement whereas the $\mathrm{OH}$ concentration for FACE C is lower by about 30\% during the first $100 \mu$ s. Similar n- and isoparaffin content present in PRF 84 and FACE A leads to similar $\mathrm{OH}$ profiles. The lower $\mathrm{OH}$ concentration for FACE C over the early time, however, does not appear to significantly affect the ignition delay time. 
The three stable molecules measured here, $\mathrm{CO}, \mathrm{H}_{2} \mathrm{O}$ and $\mathrm{CO}_{2}$, are important reaction progress markers. It can be observed from Fig. 5 (b-d) that these species evolve quite similarly in time for all three fuels studied. Post-ignition plateau values of these species are slightly higher for PRF 84 compared to FACE A, with $\mathrm{OH}, \mathrm{CO}$ and $\mathrm{CO}_{2}$ being $15 \%, 9 \%$ and $6 \%$ higher, respectively. The similarities in global reactivity of the three fuels, indicated by similarities in ignition delay (Fig. 4), can now be explained based on the observation that the local reactivity markers also evolve similarly during the induction period. These fuels may exhibit some differences in higher carbon-containing species produced during initial fuel decomposition, but these differences did not affect the global reactivity as well as the local reactivity markers (Fig. 4, Fig. 5) in this high-temperature study. All speciation data presented here can be found in the Supplementary Material.

Measured PRF 84 species profiles are compared with those predicted by Mehl et al. [5] gasoline surrogate mechanism and Bieleveld et al. [36] PRF mechanism in Fig. 6. The correct prediction of $\mathrm{OH}$ radicals is very important, particularly in high temperature regime. The rates of production (ROP) of reaction progress markers, such as $\mathrm{H}_{2} \mathrm{O}\left(\mathrm{OH}+\mathrm{H}_{2} \leftrightarrow \mathrm{H}+\mathrm{H}_{2} \mathrm{O}, \mathrm{CH}_{4}+\mathrm{OH}\right.$ $\left.\leftrightarrow \mathrm{CH}_{3}+\mathrm{H}_{2} \mathrm{O}\right)$ and $\mathrm{CO}_{2}\left(\mathrm{CO}+\mathrm{OH} \leftrightarrow \mathrm{CO}_{2}+\mathrm{H}\right)$, are strongly dependent on the $\mathrm{OH}$ radical concentration at these high temperatures. It can be seen from Fig. 6 that Mehl et al. [5] mechanism (dashed lines) captures the $\mathrm{OH}$ experimental profile very well at the highest temperature of this study $(1526 \mathrm{~K})$, although there is considerable under-prediction $(\sim 50 \%)$ at earlier times $(20-100 \mu \mathrm{sec})$. Bieleveld et al. [36] mechanism (dotted lines in Fig. 6) significantly overpredicts the early-time concentration of all measured species and thus gives much shorter ignition delay time. 
Fig. 7 shows Mehl et al. [5] model predictions for different species as a function of temperature. As temperature is decreased, the $\mathrm{OH}$ model predictions start to deviate further from the $\mathrm{OH}$ experimental profiles; see the comparison at $1459 \mathrm{~K}, 1436 \mathrm{~K}$ and $1397 \mathrm{~K}$. Similar observations can be made for time-histories of $\mathrm{CO}, \mathrm{H}_{2} \mathrm{O}$ and $\mathrm{CO}_{2}$. At $1526 \mathrm{~K}$, Mehl et al. [5] mechanism overpredicts $\mathrm{CO}$ at early times, though excellent agreement can be seen between the simulated and experimental $\mathrm{CO}_{2}$ and $\mathrm{H}_{2} \mathrm{O}$ profiles. Importantly, the model fails to capture any of the reaction progress markers at lower temperatures. These trends are also depicted in Fig. 4, where the discrepancy between PRF 84 measured and Mehl et al. [5] simulated ignition delay times increases as temperature decreases.

Hydroxyl sensitivity (Fig. 8) and rate-of-production (not shown here) analyses performed for PRF 84 show that $\mathrm{OH}$ is consumed by propene and iso-butene after the initial fuel decomposition and abstraction reactions. Propene and iso-butene are thus $\mathrm{OH}$ radical scavenging species and produce resonantly-stabilized allyl $\left(\mathrm{C}_{3} \mathrm{H}_{6}+\mathrm{OH} \leftrightarrow \mathrm{C}_{3} \mathrm{H}_{5}-\mathrm{A}+\mathrm{H}_{2} \mathrm{O}\right)$ and relatively unreactive allene $\left(\mathrm{IC}_{4} \mathrm{H}_{8}+\mathrm{OH} \leftrightarrow \mathrm{IC}_{4} \mathrm{H}_{7}+\mathrm{H}_{2} \mathrm{O}, \mathrm{IC}_{4} \mathrm{H}_{7} \leftrightarrow \mathrm{C}_{3} \mathrm{H}_{4}-\mathrm{A}+\mathrm{CH}_{3}\right)$, respectively. Thus the rates of reactions involving propene, iso-butene, allyl, and allene can affect the overall fuel reactivity. The uncertainty in unimolecular decomposition and hydrogen abstraction rates of these species may contribute to the differences between the experimental and modeled speciation trends. A multi-institution study of propene and iso-butene ignition is currently underway to help address these issues (private communication with Dr. Henry Curran, NUI Galway). Mehl et al. [5] gasoline surrogate mechanism captures n-heptane reactivity quite accurately (Fig. 3, Fig. 4), and thus the discrepancy between measured and simulated PRF profiles can be the result of deficiencies in the iso-octane sub-mechanism or synergetic effects between the n-heptane and iso-octane chemistry. 


\section{Conclusions}

Oxidation characteristics of two highly paraffinic gasoline fuels, with similar octane rating, were measured and compared with the measured oxidation characteristics of a PRF surrogate. The PRF surrogate successfully captured the overall global reactivity of the fuel primarily due to paraffinic nature of the gasolines studied here. Multi-species time histories $(\mathrm{CO}$, $\mathrm{H}_{2} \mathrm{O}, \mathrm{OH}$ and $\mathrm{CO}_{2}$ ) measurements revealed similar trends for all three fuels. The need for refining propene/iso-butene oxidation chemistry is pointed out. It is also illustrated for Mehl et al. [5] mechanism that the iso-octane chemistry and the PRF kinetic mechanism require further refinement. We believe this study provides valuable validation data for the benchmark gasolines and their PRF surrogate and will help in the refinement and development of predictive kinetic mechanisms for practical fuels. In future, we plan to apply this experimental strategy to several other practical fuels and expand the experimental conditions to lower temperatures and higher pressures.

\section{Acknowledgements}

We would like to acknowledge the funding provided Saudi Aramco under the FUELCOM program and by King Abdullah University of Science and Technology (KAUST). We are also grateful to Professor S.M. Sarathy for useful discussions and in helping with procurement of FACE fuels.

Supplementary Material: An Excel file containing ignition delay time and species time-history data is included. 


\section{References}

[1] Pitz WJ, Cernansky NP, Dryer FL, Egolfopoulos FN, Farrell JT, Friend DG, Pitsch H. Development of an experimental database and chemical kinetic models for surrogate gasoline fuels.SAE 2007-01- 0175.

[2] Wallington TJ, Kaiser EW, Farrell JT. Automotive fuels and internal combustion engines: a chemical perspective. Chem Soc Rev 2006; 35(4): 335-47.

[3] Curran HJ, Gaffuri P, Pitz WJ, Westbrook CK. A comprehensive modeling study of nheptane oxidation. Combust Flame 1998; 114(1-2): 149-77.

[4] Curran HJ, Gaffuri P, Pitz WJ, Westbrook CK. A comprehensive modeling study of isooctane oxidation. Combust Flame 2002; 129(3): 253-80.

[5] Mehl M, Pitz WJ, Westbrook CK, Curran HJ. Kinetic modeling of gasoline surrogate components and mixtures under engine conditions. Proci Combust Inst 2011; 33(1): 193-200.

[6] Fieweger K, Blumenthal R, Adomeit G. Shock-tube investigations on the self-ignition of hydrocarbon-air mixtures at high pressures, in: Proci Combust Inst ; 1994(1): 1579-85.

[7] Fieweger K, Blumenthal R, Adomeit G, Self-ignition of SI engine model fuels: a shock tube investigation at high pressure. Combust Flame 1997; 109(4): 599-619.

[8] Griffiths JF, Halford-Maw PA, Mohamed C. Spontaneous ignition delays as a diagnostic of the propensity of alkanes to cause engine knock. Combust Flame 1997; 111(4): 327-37.

[9] Gauthier BM, Davidson DF, Hanson RK. Shock tube determination of ignition delay times in full-blend and surrogate fuel mixtures. Combust Flame 2004; 139(4): 300-11.

[10] He X, Donovan MT, Zigler BT, Palmer TR, Walton SM, Wooldridge MS, Atreya A. An experimental and modeling study of iso-octane ignition delay times under homogeneous charge compression ignition conditions. Combust Flame 2005; 142(3): 266-75.

[11] Kukkadapu G, Kumar K, Chih-Jen S, Mehl M, Pitz WJ. Autoignition of gasoline and its surrogates in a rapid compression machine. Proci. Combust Inst 2013; 34(1): 345-52.

[12] Sarathy SM, Kukkadapu G, Mehl M, Wang W, Javed T, Park S et al. Ignition of alkane-rich FACE gasoline fuels and their surrogate mixtures. Proci Combust Inst 2014 2014; 35(In Press, Corrected Proof).

[13] Anand K, Ra Y, Reitz RD, Bunting B. Surrogate model development for fuels for advanced combustion engines. Energy Fuels 2011; 25(4): 1474-84. 
[14] Davidson DF, Hong Z, Pilla GL, Farooq A, Cook RD, Hanson RK. Multi-species timehistory measurements during n-heptane oxidation behind reflected shock waves. Combust Flame 2010; 157(10): 1899-905.

[15] Davidson DF, Hong Z, Pilla GL, Farooq A, Cook RD, Hanson RK. Multi-species timehistory measurements during n-dodecane oxidation behind reflected shock waves. Proci Combust Inst 2011; 33(1): 151-57.

[16] Haylett DR, Davidson DF, Cook RD, Hong Z, Ren W, Pyun SH, Hanson RK. Multi-species time-history measurements during n-hexadecane oxidation behind reflected shock waves. Proci Combust Inst 2013; 34(1): 369-76.

[17] MacDonald ME, Davidson DF, Hanson RK, Pitz WJ, Mehl M, Westbrook CK.

Formulation of an RP-1 pyrolysis surrogate from shock tube measurements of fuel and ethylene time histories. Fuel 2013; 103: 1051-59.

[18] MacDonald ME, Ren W, Zhu Y, Davidson DF, Hanson RK. Fuel and Ethylene Measurements during n-dodecane, methylcyclohexane, and iso-cetane pyrolysis in shock tubes. Fuel 2013; 103: 1060-68.

[19] CHEMKIN-PRO release 15101. Reaction Design, Inc., San Diego, CA; 2010.

[20] Sarathy SM, Javed T, Karsenty F, Heufer A, Wang W, Park S, et al. A comprehensive combustion chemistry study of 2, 5-dimethylhexane. Combust Flame 2014; 161(6): 1444-59. [21] Sajid MB, Es-sebbar Et, Javed T, Fittschen C, Farooq A. Measurement of the Rate of Hydrogen Peroxide Thermal Decomposition in a Shock Tube Using Quantum Cascade Laser Absorption Near $7.7 \mu \mathrm{m}$. Int J Chem Kinet 2014; 46(5): 275-84.

[22] Badra J, Elwardany AE, Khaled F, Vasu SS, Farooq A. A shock tube and laser absorption study of ignition delay times and $\mathrm{OH}$ reaction rates of ketones: 2-Butanone and 3-buten-2-one. Combust Flame 2014; 161(3): 725-34.

[23] Kee RJ, Rupley FM, Miller JA. The Chemical Thermodynamic Data Base, Report No. SAND87- 8215B. Sandia National Laboratories, 1987.

[24] Ren W, Farooq A, Davidson DF, Hanson RK. CO concentration and temperature sensor for combustion gases using quantum-cascade laser absorption near $4.7 \mu \mathrm{m}$. Appl Phys B 2012; 107(3): 849-60.

[25] Rothman LS, Gordon IE, Barbe A, Benner DC, Bernath PF, Birk M, et al. The HITRAN 2008 molecular spectroscopic database. J Quant Spectrosc Radiat Transfer 2009; 110(9): 533-72. 
[26] Ren W, Spearrin RM, Davidson DF, Hanson RK. Experimental and Modeling Study of the Thermal Decomposition of C3-C5 Ethyl Esters Behind Reflected Shock Waves. J Phys Chem A 2014; 118(10): 1785-98.

[27] Spearrin RM, Ren W, Jeffries JB, Hanson RK. Multi-band infrared CO2 absorption sensor for sensitive temperature and species measurements in high-temperature gases. Appl Phys B 2014; 1-11.

[28] Farooq A, Jeffries JB, Hanson RK. In situ combustion measurements of $\mathrm{H} 2 \mathrm{O}$ and temperature near $2.5 \mu \mathrm{m}$ using tunable diode laser absorption. Meas Sci Technol 2008; 19(7): 075604-14.

[29] Hong Z, Farooq A, Barbour EA, Davidson DF, Hanson RK. Hydrogen peroxide decomposition rate: a shock tube study using tunable laser absorption of $\mathrm{H} 2 \mathrm{O}$ near $2.5 \mu \mathrm{m}$. J Phys Chem A 2009; 113(46): 12919-25.

[30] Herbon JT, Hanson RK, Golden DM, Bowman CT. A shock tube study of the enthalpy of formation of OH. Proci Combust Inst 2002; 29(1): 1201-08.

[31] Li H, Owens ZC, Davidson DF, Hanson RK. A simple reactive gasdynamic model for the computation of gas temperature and species concentrations behind reflected shock waves. Int J Chem Kinet 2008; 40(4): 189-98.

[32] Chih-Jen S, Sarathy SM, Veloo PS, Westbrook CK, Egolfopoulos FN. Effects of fuel branching on the propagation of octane isomers flames. Combust Flame 2012; 159(4): 1426-36. [33] Liu N, Sarathy SM, Westbrook CK, Egolfopoulos FN. Ignition of non-premixed counterflow flames of octane and decane isomers. Proci Combust Inst 2013; 34(1): 903-10. [34] Silke EJ, Curran HJ, Simmie JM. The influence of fuel structure on combustion as demonstrated by the isomers of heptane: a rapid compression machine study. Proci Combust Inst 2005; 30(2): 2639-47.

[35] Dooley S, Won SH, Heyne J, Farouk TI, Ju Y, Dryer FL, et al. The experimental evaluation of a methodology for surrogate fuel formulation to emulate gas phase combustion kinetic phenomena. Combust Flame 2012; 159(4): 1444-66.

[36] Bieleveld T, Frassoldati A, Cuoci A, Faravelli T, Ranzi E, Niemann U, Seshadri K. Experimental and kinetic modeling study of combustion of gasoline, its surrogates and components in laminar non-premixed flows. Proci Combust Inst 2009; 32(1): 493-500. 
[37] Ranzi E, Frassoldati A, Grana R, Cuoci A, Faravelli T, Kelley AP, Law CK. Hierarchical and comparative kinetic modeling of laminar flame speeds of hydrocarbon and oxygenated fuels. Prog Energy Combust Sci 2012; 38(4): 468-501. 


\section{Tables}

\begin{tabular}{|c|c|c|c|}
\hline Fuel Properties & FACE Gasoline A & FACE Gasoline C & PRF 84 \\
\hline RON & 83.5 & 84.7 & 84 \\
\hline MON & 83.6 & 83.6 & 84 \\
\hline Sensitivity & -0.1 & 1.1 & 0 \\
\hline Avg. mol. wt. & 97.8 & 97.2 & 112 \\
\hline \multicolumn{3}{|c|}{ Hydrocarbon Type, liquid mol\% } \\
\hline n-Paraffins & 13.2 & 28.6 & 17.6 \\
\hline iso-Paraffins & 83.7 & 65.1 & 82.4 \\
\hline Aromatics & 0.3 & 4.4 & 0 \\
\hline Alkenes & 0.4 & 0.4 & 0 \\
\hline Cycloalkanes & 2.4 & 1.5 & 0 \\
\hline H/C ratio & 2.29 & 2.27 & 2.26 \\
\hline
\end{tabular}

Table 1: Properties of FACE gasoline fuels and PRF surrogate. The hydrocarbon types for FACE A and $\mathrm{C}$ were determined by Detailed Hydrocarbon Analysis (DHA) technique. 


\section{Figures}

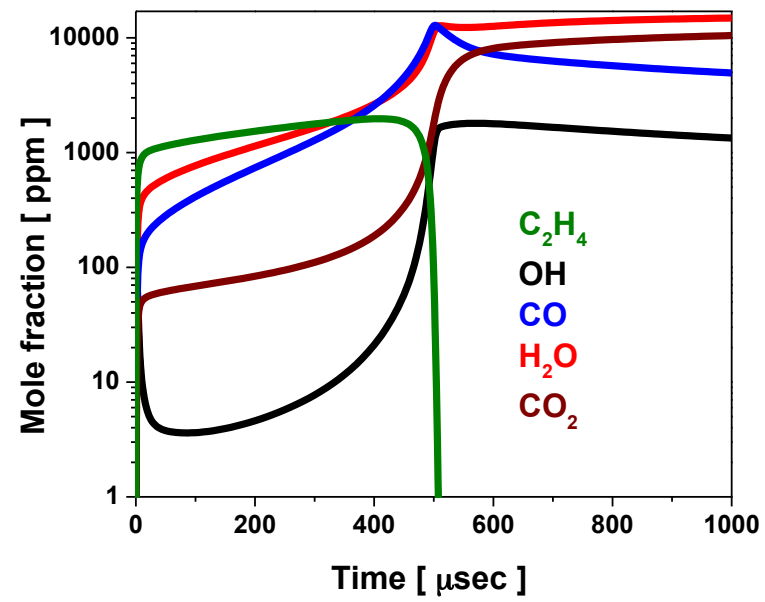

Fig. 1: Simulated profiles of major species formed during the oxidation of PRF 84. Mixture:

$0.2 \% \mathrm{PRF} 84 / \mathrm{O}_{2} / \operatorname{Ar}(\Phi=1), \mathrm{T}=1500 \mathrm{~K}, \mathrm{P}=2 \mathrm{~atm}$. Constant internal energy and volume (constant UV) simulations performed in Chemkin-Pro [19] using Mehl et al. mechanism [5]. 

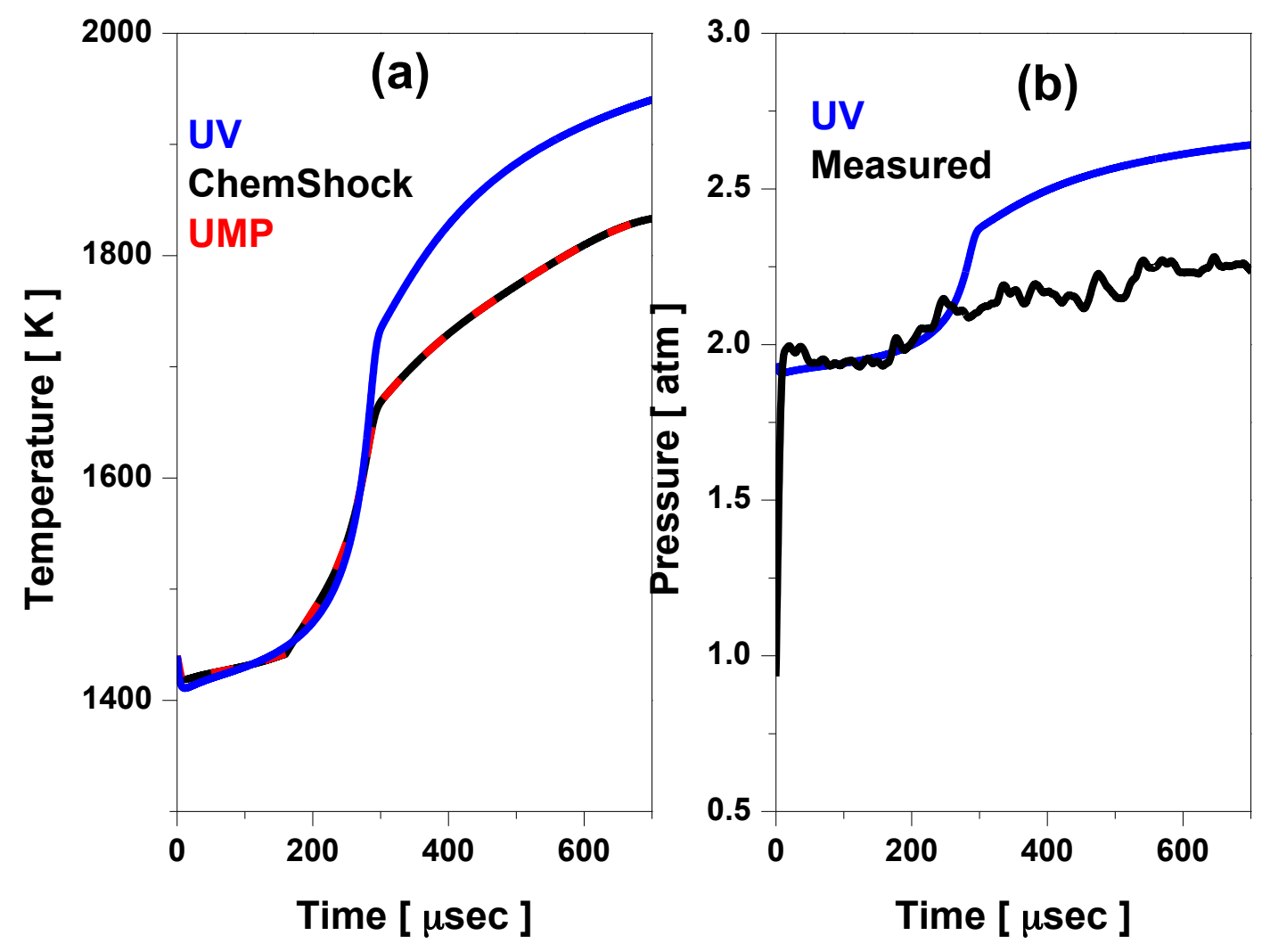

Fig. 2: Comparison of modeled (a) temperature and (b) pressure using various gasdynamic models $(\mathrm{UV}=$ constant internal energy and volume, $\mathrm{UMP}=$ constant internal energy with measured pressure) during the oxidation of $0.2 \%$ n-heptane $/ \mathrm{O}_{2} / \operatorname{Ar}(\Phi=1), \mathrm{T}=1440 \mathrm{~K}, \mathrm{P}=$ $1.94 \mathrm{~atm}$. Temperature output using ChemShock [31] code is also shown. Simulations performed using Mehl et al. [5] mechanism. 


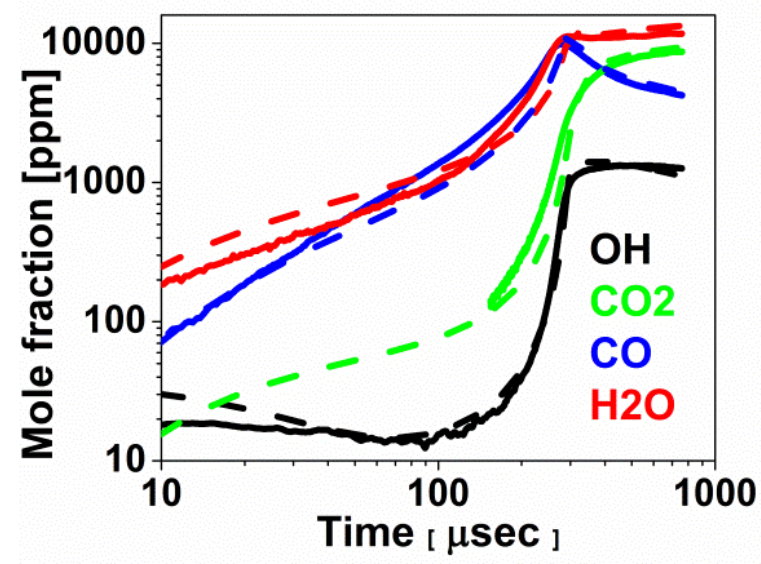

Fig. 3: Comparison of model prediction with experimentally measured species profiles for $0.2 \%$ n-heptane $/ \mathrm{O}_{2} / \mathrm{Ar}(\Phi=1), \mathrm{T}=1440 \mathrm{~K}, \mathrm{P}=1.94 \mathrm{~atm}$; solid lines: experimental profiles, dashed lines: Constant UV simulations using Mehl et al. [5] mechanism. 


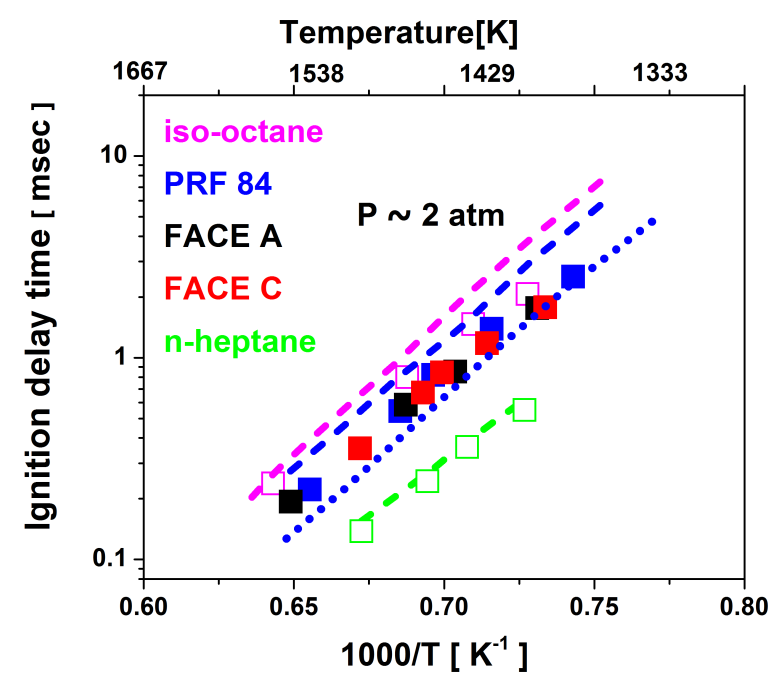

Fig. 4: Ignition delay times during the oxidation of stoichiometric mixtures with $0.2 \%$ fuel (isooctane, PRF 84, FACE A, FACE C, n-heptane) / $\mathrm{O}_{2} / \mathrm{Ar}, \mathrm{P} \approx 2$ atm; Scatter: Experimental, Dashed lines: Mehl et al. [5] mechanism. Dotted line: Bieleveld et al. mechanism [36] 

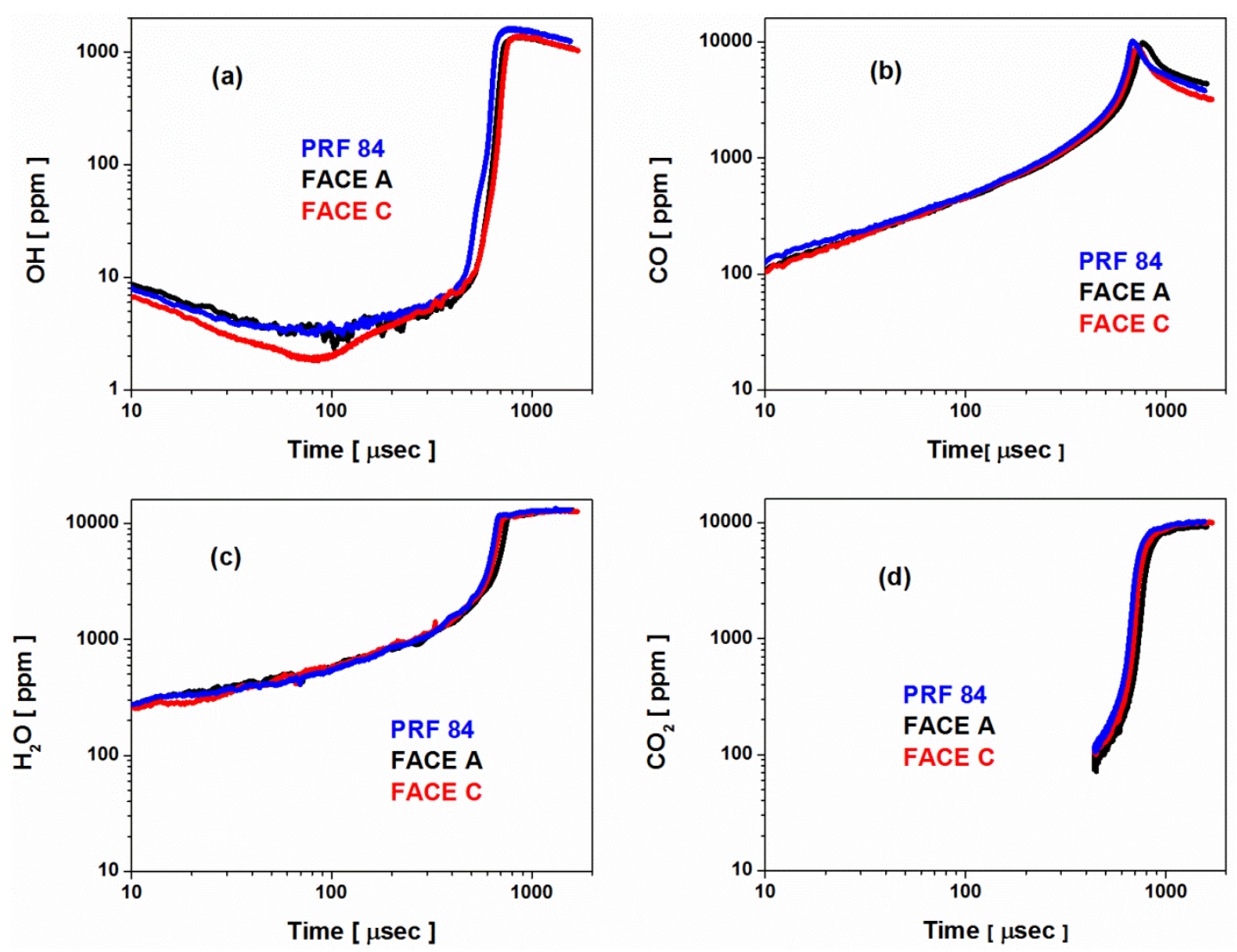

Fig. 5: Measured species profiles during the oxidation of $0.2 \%$ fuel, $\Phi=1, \mathrm{P} \approx 2 \mathrm{~atm}$; Reflectedshock temperatures are PRF 84: 1459 K; FACE A: $1455 \mathrm{~K}$; FACE C: $1443 \mathrm{~K}$. Note that the $\mathrm{CO}_{2}$ data are not available at early times due to the 100 ppm detection limit of the $\mathrm{CO}_{2}$ diagnostic used here. 


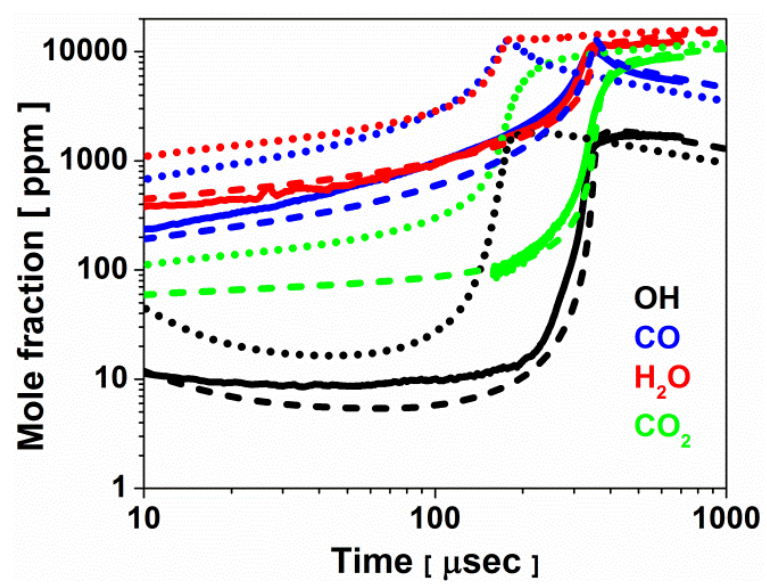

Fig. 6: Comparison of multi-species measurements with kinetic simulations during the oxidation of $0.2 \% \mathrm{PRF} 84 / \mathrm{O}_{2} / \mathrm{Ar}(\Phi=1), \mathrm{T}=1526 \mathrm{~K}, \mathrm{P}=2 \mathrm{~atm}$. Solid lines: Measurements, Dashed lines: Mehl et al. [5] simulations, Dotted lines: Bieleveld et al. [36] simulations. 

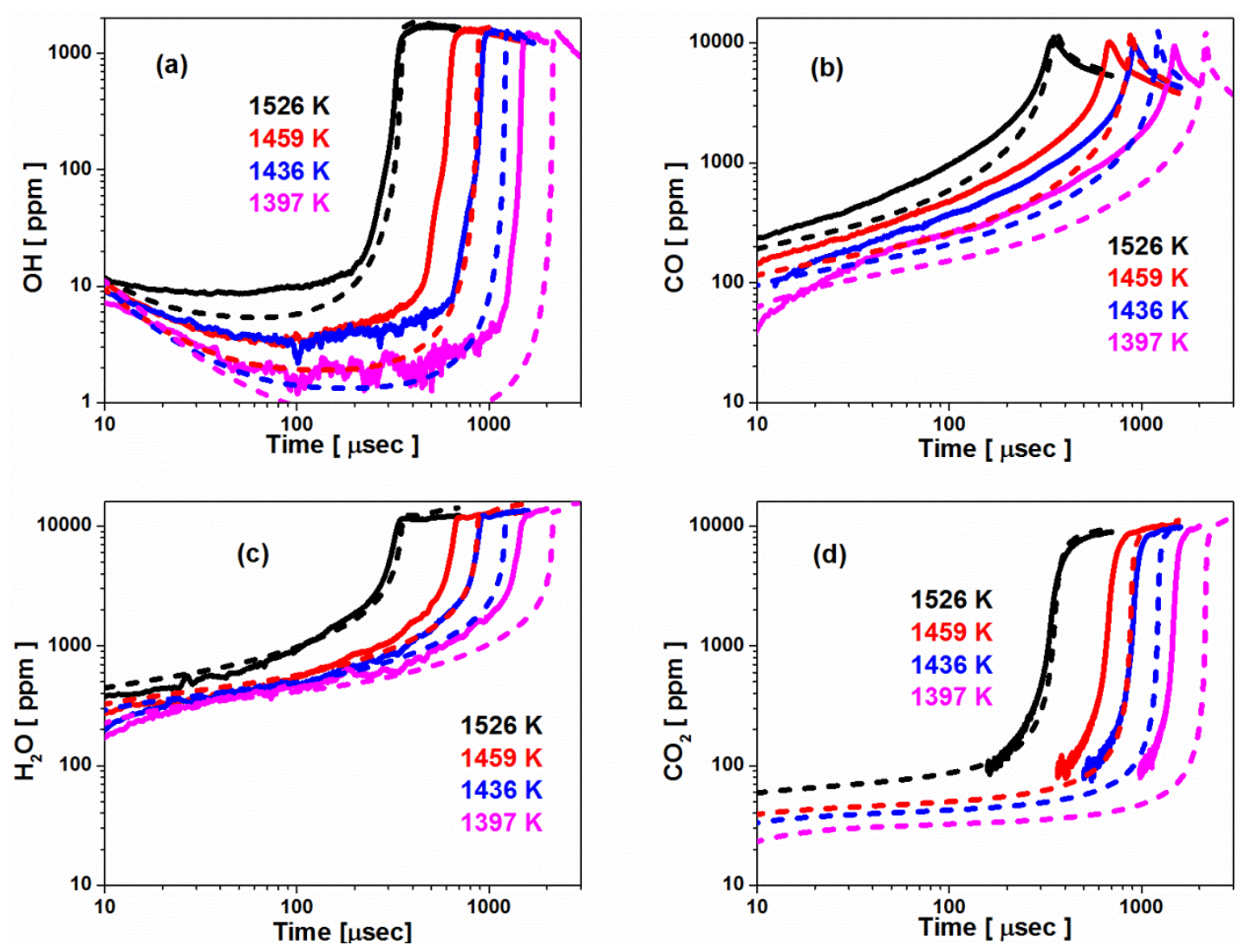

Fig. 7: Comparison of measured profiles with kinetic simulations during the oxidation of $0.2 \%$ PRF84/ $\mathrm{O}_{2} / \operatorname{Ar}(\Phi=1)$, Solid lines: Measurements, Dashed lines: Mehl et al. [5] simulations. 


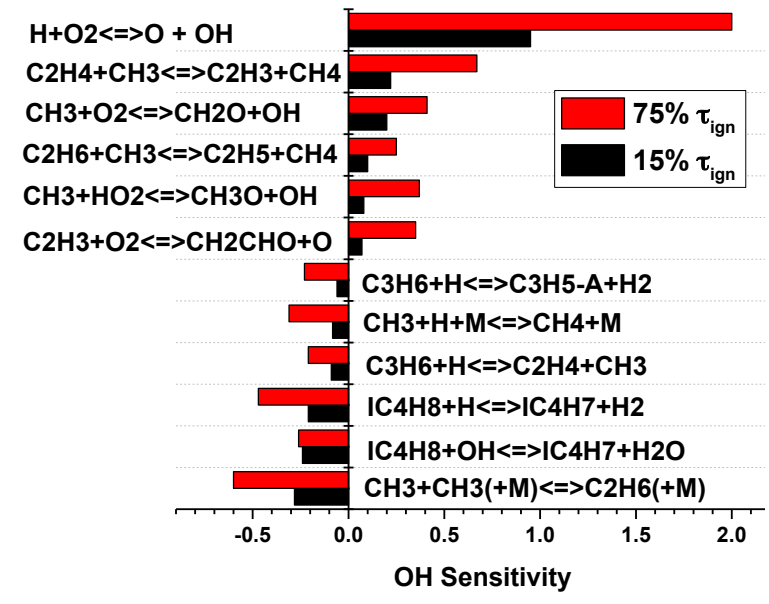

Fig. 8: Hydroxyl sensitivity at two instants: $15 \%$ and $75 \%$ of the predicted ignition delay time. $0.2 \% \operatorname{PRF} 84 / \mathrm{O} 2 / \operatorname{Ar}(\Phi=1), \mathrm{T}=1430 \mathrm{~K}, \mathrm{P}=2 \mathrm{~atm}$. 